100\%. Với đặc tính cộng hưởng từ, khảo sát CHT mạch máu được xem là một trong những biện pháp chẩn đoán chính xác và giúp có thể đinh danh phân loai $A V M$ và VM theo nhiêu tác giả trên thế giới. Có hai loại khảo sát $\mathrm{CHT}$ mạch máu: CHT mạch máu động học có tái tạo cấu trúc 3 chiều, và $\mathrm{CHT}$ mạch máu theo thời gian (time resolved MRA). Với loại đầu, mốc 6 giây được xem là thời gian bắt thuốc sớm hay muộn, và theo kỹ thuật này, độ nhạy và độ đặc hiệu đế phân biệt dòng cao và dòng thấp lần lượt là $83 \%$ và $95 \%$. Mặc dù $\mathrm{CHT}$ mạch máu có giá trị chẩn đoán rất tốt, giúp phân loại dị dạng mạch máu dòng cao và thấp, cũng như phân loại của dị dạng động tĩnh mạch và dị dạng tĩnh mạch ${ }^{6,7}$.

\section{KẾT LUÂ̂N}

Dị dạng mạch máu ngoại biên có nhiều phân loại nhưng phẩn loại mới và có nhiều ý nghĩa cho lâm sàng là phân loại ISSVA 2014. CHT rất có giá trị trong phát hiện, chẩn đoán, phân loại và theo dõi sau điều trị dị dạng mạch máu ngoại biên.

\section{TÀI LIÊU THAM KHẢO}

1. Lee Byung-B., Laredo J., Neville R. F., et al. (2015), "Epidemiology of vascular malformations", In: Hemangiomas and Vascular Malformations, Springer, pp. 165-169.

2. Yakes W. F. (2015), "Yakes' AVM classification system". Journal of Vascular and Interventional Radiology, 26 (2), pp. S224.

3. Nguyễn Công Mính (2013), "Đánh giá điều trị di dạng mạch máu bẩm sinh ở người lớn trong 6 năm (2005-2010)". Tạp chí Y học TPHCM, 17.

4. Tasnádi G. (1993), "Epidemiology and etiology of congenital vascular malformations". Semin Vasc Surg, 6 (4), pp. 200-3.

5. Arnold R., Chaudry G. (2011), "Diagnostic imaging of vascular anomalies". Clin Plast Surg, 38 (1), pp. 21-9.

6. Rak K. M., Yakes W. F., Ray R. L., et al. (1992), "MR imaging of symptomatic peripheral vascular malformations". AJR Am J Roentgenol, 159 (1), pp. 107-12.

7. Ohgiya Y., Hashimoto T., Gokan T., et al. (2005), "Dynamic MRI for distinguishing high-flow from low-flow peripheral vascular malformations". AJR Am J Roentgenol, 185 (5), pp. 1131-7.

\title{
MộT Số ĐĂC ĐIỂM VỀ HÌNH DANG XƯƠ'NG CHÍNH MŨI VÀ MÔ HỌC VÙNG KHỚP MŨI TRÁN TRÊN THI THỂ NGƯỜI VIẸTT TRƯỞNG THÀNH
}

\author{
Hồ Nguyễn Anh Tuấn*, Võ Văn Hải**, \\ Cao Nguyễn Hoài Thương*, Phạm Đăng Diệu*
}

\section{TÓM TẮT}

Muc tiêu: Xác định tỉ lệ các hình dang xương mũi và đặc điểm mô học khớp mũi trán trên thi thể người Việt trưởng thành. Phương pháp: Nghiên cứu mố tả, khảo sát xương mũi từ xác ướp formalin $10 \%$ của người Việt trưởng thành, tại bô môn Giải phẫu Trường Đại học y khoa Pham Ngọc Thach từ tháng 06/2019 đển tháng 01/202i. Nghiên cứu xác định các hình dạng của xương mũi khi nhìn thẳng, nhìn nghiêng, và hình dạng của khớp mũi trán. Quá trình xử lý và nhuộm mô HE (hematoxylin - eosin) được thực hiện tại Viện 69 (Bộ tư lệnh bảo vệ lăng Hồ Chủ Tịch). Kết quả: Nghiên cứu khảo sát được 33 mấu xương mũi với 45,5\% là nữ, độ tuổi dao động từ 20 - 87 tuổi, với tuổi trung bình là 65 tuổi. Tỉ lệ xương mũi có điểm gù xương là 24,2\% với đa số nắm ở chính giữa xương (chiếm 75\%). Đa số xương mũi người Việt khi nhìn nghiêng có hình $V$ với $81,8 \%$. Hình dạng xương mũi nhìn thẳng chủ yếu là loại $\mathrm{A}(57,6 \%)$ và loại $\mathrm{B}$

*Trường $Đ H$ Y khoa Pham Ngoc Thạch

**Đai hoc Y Dướ TP Hồ Chí Minh

Chịu trcachs nhiệm chính: Hồ Nguyễn Anh Tuấn

Email: hnat503@pnt.edu.vn

Ngày nhận bài: 26/3/2021

Ngày phản biên khoa hoc: 10/5/2021

Ngày duyệt bài: 21/5/2021
$(30,3 \%)$. Về hình dang khớp mũi trán, chiếm tỉ lê cao nhất là hình $B$ với $45,5 \%$, sau đó là hình $A$ và hình $C$ với tî lệ tương ứng là $21,2 \%$ và $15,1 \%$. Hình ảnh 6 mẫu mố học tại khớp mũi trán cho thây $100 \%$ là khớp cài răng lược. Khoảng cách khe khớp trung bình là $0,78 \pm 0,22 \mathrm{~mm}$; bề dày ngoại cốt mạc tại điểm xương trán và xương mũi lần lượt là $0,38 \pm 0,13 \mathrm{~mm}$ và 0,42 $\pm 0,15 \mathrm{~mm}$. Nghiên cứu tìm thấy mối tương quan giữa bề dày ngoại cốt mạc tại điểm xương trán với điểm xương mữi và trung điểm khe khớp. Kết luân: Cần có các nghiên cứu chi tiết hơnvề giải phẫu đại thể và vì thể của xương mũi với số liệu lớn để có thể góp phần vào nhân dạng nhân chủng và ứng dụng trong tạo hình thẩm mỹ mũi.

Tư khóa: Hình dạng xương mũi, khớp mũi trán, mô học mũi, bề dày ngoại cốt mạc.

\section{SUMMARY}

THE CHARACTERISTICS ABOUT THE NASAL

BONE SHAPE AND THE HISTOLOGICAL \section{FEATURES OF THE FRONTONASAL SUTURE} OF THE VIETNAMESE CADAVERS

Objectives: To determine the ratio of the nasal bone shapeand the histological features of the frontonasal suture. Methods: cross-sectional descriptive studies on the nasal bones from dried Vietnameses corpses at the Anatomy Department of Pham Ngoc Thach University of Medicine from June 
2019 to January 2021. By the directly examination of the nasal bone and frontonasal suture on the straight, the right and the left side, the histological examination with HE in the 69 department. Results: There are 33 nasal bones, with $45.5 \%$ female, the age range from 20 to 87 years old, the average age is 65 years. The proportion of nasal bones with $\mathrm{K}$ is $24.2 \%$. Most of the nasal bones are the V-shaped with $81.8 \%$ on the lateral side. The major shape is type $A(57.6 \%)$ and type B $(30.3 \%)$ on the straight side. About the frontonasal suture, the major ratio is the $B$ type with $45.5 \%$. On the six histological samples examination, the frontonasal sutures are dense. The average distance of the joint is $0.22 \mathrm{~mm}$; the periosteum in the nasal and frontal bones is alternatively $0,38 \pm 0,13 \mathrm{~mm}$ and $0,42 \pm 0,15 \mathrm{~mm}$. There is the correlation between the periosteum thickness at three sites: the nasal bone, the frontal bone and the nasion. Conclusion: Macro and micro anatomical characteristics of the nasal bone and frontonasal sutures is very important in the anthropometry and rhinoplasty. We need more research about these featuresin the future to determine them.

Key words: nasal anthropometry, frontonasal suture, nasal shape, histological, periosteum.

\section{I. ĐẶT VẤN ĐỀ}

Xương mũi là một cấu trúc rất quan trọng, quyết định dáng của mũi và là vị trí xương nổi bật nhất trên khuôn mặt. Xương mũi nằm tiếp giáp với xương trán ở phía trên và với xương hàm trên ở phía dưới, tạo thành một khối hài hòa trên khuôn mặt. Ngoại trừ ảnh hưởng về mặt thẩm mỹ thì hình dạng và độ rộng của xương mũi còn có tác động đáng kể đến hô hấp của con người ${ }^{(1)}$.

Vì có sự khác biệt đặc trưng giữa các chủng tộc về hình dạng và kích thước của mũi, nên có thể xương mũi và kích thước xương cũng sẽ có một số khác biệt(2). Một số tác giả trên thế giới cho rằng việc nghiên cứu về hình thái học xương mũi sẽ giúp cung cấp những thông tin hữu ích cho lĩnh vực Tai mũi họng, Nhân chủng học và nhận dạng Pháp yvì những thông tin này có thể được áp dụng để phân biệt giới tính và chủng tộc ${ }^{(1)}$. Thậm chí có những tác giả nhưRogersvà Williams (3) còn cho rằng hình dạng và kích thước xương mũi là một chỉ số quan trọng để xác định giới tính. Tuy nhiên, đến thời điểm hiện tại, thậm chí trên thế giới cũng có rất ít các nghiên cứu về chủ đề này. Tại Việt Nam, bước đâu chỉ mới có một số đề tài khảo sát các nội dung riêng lẻ như tác giả Trần Thị Anh Tú( ${ }^{4}$, chưa có nghiên cứu nào hoàn toàn tập trung nghiên cứu về hình thái và kích thước xương mũi người Việt. Vì vậy, chúng tôi thực hiện nghiên cứu với mục tiêu xác định tỉ lệ các hình dạng xương mũi và mô tả mô học vùng khớp mũi trán trên thi hài người Việt trưởng thành nhằm cung cấp thêm những thổng tin cần thiết ứng dụng cho lĩnh vực thẩm mỹ mũi đồng thời làm phong phú thêm nguồn tài liệu tham khảo cho khoa học nhận dạng và pháp $y$.

\section{II. ĐỐI TƯợNG VÀ PHƯƠNG PHÁP NGHIÊN CỨU}

2.1. Thiết kế nghiên cứu: Nghiên cứu mô tả.

2.2. Đối tượng nghiên cứu: Xương mũi từ xác ướp formalin $10 \%$ của người Việt trưởng thành, tại bộ môn Giải phẫu Trường Đại học y khoa Phạm Ngọc Thạch.

2.3. Thời gian nghiên cứu: Từ tháng 11/2020 - tháng 01/2021.

2.4. Cỡ mấu: 33 mẫu xương mũi +6 mẫu mô học xương mũi.

2.5. Kỹ thuật chọn mẫu: Chọn mẫu thuận tiện trên các xác ướp formalin $10 \%$ của người Việt trưởng thành,tại trường Đại học $Y$ khoa Phạm Ngọc Thạch.

\subsection{Tiêu chuẩn chọn mẫu}

Tiêu chuẩn chọn vào: Xác người Việt trưởng thành trên 18 tuổi, còn nguyên vẹn vùng tháp mũi và chưa phẫu thuật trên vùng mũi.

Tiêu chuẩn loại ra: Loại bỏ những xác bi biến dang tháp mũi, u bướu hay bất thường về giải phẫu vùng mặt.

\subsection{Phương pháp thu thập số liệu}

Giải phẫu đại thể. Phẫu tích trên 33 thi hài khô và tươi, sau khi bộc lộ xương mũi thì xác địnhcác hình dạng xướng mũi như sau: nhìn nghiêng theo tác giả Lazovic ${ }^{(5)}$, nhìn thẳng theo tác giả Hwang T.S (hình 1$)^{(1)}$, hình dạng khớp mũi tránđầy đủ theo tác giả Oetteking (hình 2) và rút gọn (hình 3 ) theo tác giả Hefner J.T ${ }^{(6)}$.

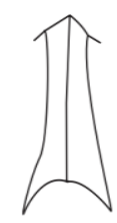

A

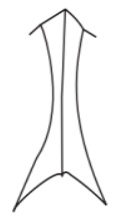

B

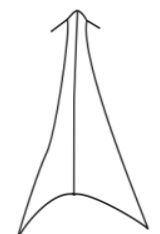

C

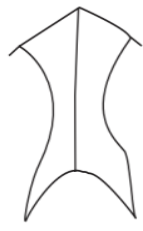

D

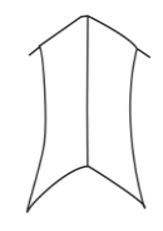

E

\section{Hình 1. Hình dạng xương mũi nhìn thẳng} theo Hwang T.S (1)

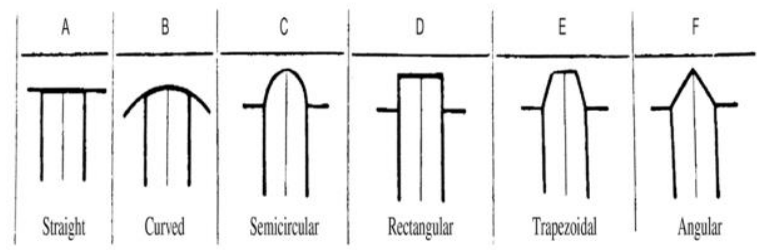

Hình 2. Hình dạng khớp mũi trán đầy đủ theo Oetteking(6) 

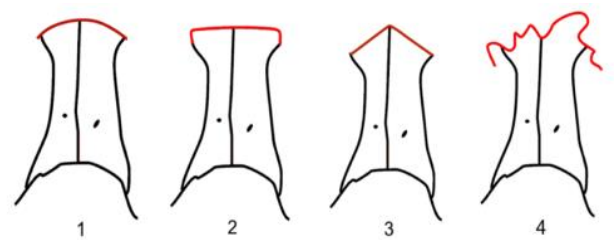

Hình 3. Hình dạng khớp mũi trán rút gọn theo Hefner J.T(6)

Giải phẫu vi thể. Trên thi hài khô bảo quản bằng formalin $10 \%$,việc khảo sát mô học được thực hiện qua các bước sau:

-Bước 1: bộc bộ vùng giữa mặt, dùng đục, cắt toàn bộ vùng gốc mũi với giới hạn trên là đường ngang qua đầu trong 2 cung mày, 2 đường ngoài dọc theo bờ ngoài xương mũi, cánh mũi hai bên và giới hạn dưới dọc theo bờ dưới cánh mũi và chân trụ mũi. Tất cả được cố định formalin $10 \%$.

- Bước 2: Tất cả mẫu khảo sát sẽ được xử lý theo quy trình cắt lọc mô học và nhuộm mô $\mathrm{HE}$ (hematoxylin - eosin) được thực hiện tại Viện 69 (Bộ tư lệnh bảo vệ lăng Hồ Chủ Tịch).

- Bước 3: Các mẫu mô đã được cắt lọc và xử lý sẽ được quan sát dưới kính hiển vi quang học và đo đạc các khoảng cách khe khớp, độ dày ngoại cốt mạc tại điểm xương mũi, điểm xương trán và trung điểm khe khớp bằng phần mềm Image J.

2.8. Phương pháp xử lý và phân tích số liệu. Số liệu được mô tả dưới dạng tần số và tỉ lệ \% với các biến định tính; trung bình và độ lệch chuẩn với các biến định lượng. Sử dụng kiểm định chính xác Fisher để xác định sự khác biệt về hình dạng xươngnhìn nghiêng theo giới, kiểm định T-test để xác định sự khác biệt này theo tuổi.

Kiểm định Mann - Whitney để xác định sự khác biệt về hình dạng xương và khớp nhìn thẳng theo giới, điểm gù xương; tương quan Spearman để xác định sự khác biệt này theo tuổi.

Mối liên quan giữa các kích thước bề dày cốt mạc tại khớp mũi trán được xác định bằng hệ số tương quan ( $r$ ) và xây dựng phương trình hồi quy.

2.9. Đạo đức trong nghiên cứu. Nghiên cứu đã được chấp thuận của Hội đồng đạo đức trong nghiển cứu y sinh học Trường Đại học $\mathrm{Y}$ khoa Phạm Ngọc Thạch theo Quyết định số 66/HĐĐĐ ngày 10/05/2019.

\section{KẾT QUẢ NGHIÊN CỨU}

3.1. Đặc điểm của mẫu nghiên cứu. Nghiên cứu khảo sát được 33 mẫu xương mũi, trong đó có 31 xác khô và 2 xác tươi. Tỉ lệ nữ là $45,5 \%$, độ tuổi dao động từ $20-87$ tuổi, với tuổi trung bình là 65 tuổi. Tỉ lệ xương mũi có điểm gù xương (điểm $\mathrm{K}$ ) là $24,2 \%$ với đa số điểm K nằm ở chính giữa xương (chiếm $75 \%$ ).

\subsection{Mô tả hình dạng xương mũi}

\section{Xương mũi nhìn thẳng}

Bảng 1. Hình dạng xương mûi nhin thẳng theo giới $(n=33)$

\begin{tabular}{|c|c|c|c|}
\hline \multirow{2}{*}{} & \multicolumn{2}{|c|}{ Giới } & \multirow{2}{*}{ Tổng } \\
\cline { 2 - 3 } & $\begin{array}{c}\text { Nam } \\
\mathbf{n = 1 8}\end{array}$ & $\begin{array}{c}\text { Nũ̃ } \\
(\mathbf{n = 1 5})\end{array}$ & \\
\hline Xương mữi nhìn thăng (theo Hwang) \\
\hline Hình A & $9(50,0)$ & $10(66,7)$ & $19(57,6)$ \\
\hline Hình B & $6(33,2)$ & $4(26,7)$ & $10(30,3)$ \\
\hline Hình C & $1(5,6)$ & 0 & $1(3,0)$ \\
\hline Hình D & $1(5,6)$ & $1(6,6)$ & $2(6,1)$ \\
\hline Hình E & $1(5,6)$ & 0 & $1(3,0)$ \\
\hline Giá trị p & \multicolumn{2}{|c|}{$0,279 * * *$} & \multicolumn{3}{|c}{} \\
\hline
\end{tabular}

$(* * *)$ : Kiểm định Mann - Whitney

Đa số xương mũi nhìn thẳng của người Việt là loại có bờ ngoài xương thẳng và hơi nghiêng ở hai bên (loại $A)(57,6 \%)$ và loại loại bờ ngoài xương bị lõm (loại B) (30,3\%), các loại còn lại chiếm tỉ lệ rất thấp. Nghiên cứu chưa tìm thấy sự khác biệt về hình dạng xương mũi nhìn thẳng theo giới.

Xương mũi nhìn nghiêng

Bảng 2. Hình dạng xương mũi khi nhìn nghiêng ( $n=33)$

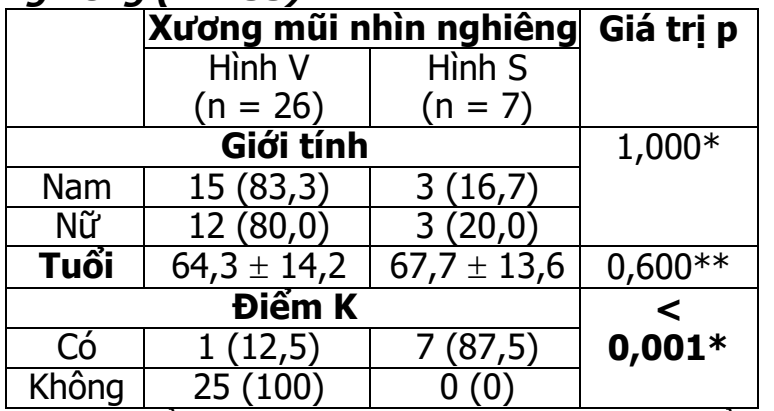

$\left({ }^{*}\right)$ : Kiểm định chính xác Fisher; $(* *)$ : Kiểm định T-test

Đa số xương mũi người Việt có hình $V$ (78,8\%) và không có sự khác biệt về hình dạng xương nhìn nghiêng theo giới tính và tuổi. Tuy nhiên, nghiên cứu tìm thấy sự khác biệt có ý nghĩa thống kê về hình dạng xương và điểm gù xương, trong đó xương mũ̃i có điểm gù thì đa số sẽ có hình $S$ khi nhìn nghiêng $(p<0,001)$.

\section{Khớp mũi trán}

Bảng 3. Hình dạng khớp mũi trán theo giới $(n=33)$

\begin{tabular}{|c|c|c|c|}
\hline \multirow[t]{2}{*}{$=$} & \multicolumn{2}{|c|}{ Giới } & \multirow[b]{2}{*}{ Tổng } \\
\hline & $\begin{array}{c}\text { Nam } \\
(n=18)\end{array}$ & $\begin{array}{c}\text { Nũ̃ } \\
(n=15)\end{array}$ & \\
\hline Khớp r & nũi trán (t & theo Oette & ig) \\
\hline
\end{tabular}




\begin{tabular}{|c|c|c|c|}
\hline Hình A & $3(16,7)$ & $4(26,7)$ & $7(21,2)$ \\
\hline Hình B & $7(38,9)$ & $8(53,3)$ & $15(45,5)$ \\
\hline Hình C & $4(22,2)$ & $1(6,7)$ & $5(15,1)$ \\
\hline Hình D & $3(16,7)$ & $0(0)$ & $3(9,1)$ \\
\hline Hình E & $0(0)$ & $2(13,3)$ & $2(6,1)$ \\
\hline Hình F & $1(5,5)$ & $0(0)$ & $1(3,0)$ \\
\hline Giá trị p p & \multicolumn{3}{|c|}{$0,236^{* * *}$} \\
\hline \multicolumn{4}{|c|}{ Khớp mũi trán (theo Hefner) } \\
\hline Loại 1 & $11(61,1)$ & $9(60,0)$ & $20(60,6)$ \\
\hline Loại 2 & $6(33,3)$ & $4(26,7)$ & $10(30,3)$ \\
\hline Loại 3 & $1(5,6)$ & $0(0)$ & $1(3,0)$ \\
\hline Loại 4 & $0(0)$ & $2(13,3)$ & $2(6,1)$ \\
\hline Giá trị p & $0,786^{* * *}$ & \\
\hline
\end{tabular}

$(* * *):$ Kiểm định Mann - Whitney

Hình danng khớp mũi trán người Viêt chiếm tỉ lệ cao nhất là hình $B$ với $45,5 \%$, sau đó là hình $A$ và hình $C$ với tỉ lệ tương ứng là $21,2 \%$ và $15,1 \%$. Các kiểu hình còn lại chiếm tỉ lệ thấp.

Khi rút gọn hình dạng khớp mũi trán thành 4 loai theo tác giả Hefner J.T thì chiếm tỉ lê cao nhất là loại 1 (khớp mũi trán có hình tròn và không có góc cạnh) với $60,6 \%$, sau đó là loại 2 (khớp có hình thẳng và gập góc 2 bên) với $30,3 \%$.

Không có sự khác biệt về hình dạng khớp mũi trán theo giới.

Bảng 4. Mối liên quan giữa hình dạng xương mưi nhìn thẳng và hình dạng khớp mưi trán $(n=33)$

\begin{tabular}{|c|c|c|c|c|c|}
\hline & \multicolumn{4}{|c|}{ Khớp mũi trán (theo Hefner) } & \multirow{2}{*}{ Giá trị $\mathrm{p}$} \\
\hline & Loại 1 & Loại 2 & Loại 3 & Loại 4 & \\
\hline \multicolumn{5}{|c|}{ Xương mũi nhìn thăng (theo Hwang) } & \multirow{6}{*}{$0,253^{\#}$} \\
\hline Hinh $A(n=19)$ & $10(52,6)$ & $7(36,8)$ & $0(0)$ & $2(10,6)$ & \\
\hline Hinh $B(n=10)$ & $7(70,0)$ & $2(20,0)$ & $1(10,0)$ & $0(0)$ & \\
\hline Hinh C $(n=1)$ & $0(0)$ & $1(100)$ & $0(0)$ & $0(0)$ & \\
\hline Hình D $(n=2)$ & $2(100)$ & $0(0)$ & $0(0)$ & $0(0)$ & \\
\hline Hình $E(n=1)$ & $1(100)$ & $0(0)$ & $0(0)$ & $0(0)$ & \\
\hline
\end{tabular}

$\left({ }^{\#}\right)$ : Tương quan Spearman

Không có mối liên quan giữa hình dạng xương và hình dạng khớp mũi trán $(p>0,05)$.

3.3. Đặc điểm mô học tại khớp mũi trán và mối liển quan với bề dày ngoại cốt mạc

Sau khi khảo sát giải phẫu đại thể xương mũi và khớp mũi trán, chúng tôi tiến hành khảo sát vi thể của 6 mẫu xương mũi. Các mẫu này được lấy từ 3 xác nam và 3 xác nữ, tuổi trung bình là 73,5 tuổi, thấp nhất 60 tuổi và cao nhất 85 tuổi. Hình ảnh mô học tại khớp cho thấy $100 \%$ là khớp cài răng lược.

Tiến hành đo khoảng cách khe khớp tại vị trí sợi Sharpey chui vào khe khớp và bề dày ngoại cốt mạc tại điểm xương trán, điểm xương mũi và trung điểm khe khớp cho kêt quả như sau:

Bảng 5. Đặc điểm mô học tại khớp mũi trán $(n=6)$

\begin{tabular}{|c|c|c|}
\hline (Đơn vị mm) & Trung bình \pm ĐLC & Min - Max \\
\hline Khoảng cách 2 mép xương tại khe khớp & $0,78 \pm 0,22$ & $0,44-1,10$ \\
\hline Bề dày ngoại cốt mạc tại điếm xương trán & $0,38 \pm 0,13$ & $0,21-0,58$ \\
\hline Bề dày ngoại cốt mạc tại điếm xương mũi & $0,42 \pm 0,15$ & $0,18-0,61$ \\
\hline Bề dày ngoại cốt mạc tại trung điếm khe khớp & $0,39 \pm 0,13$ & $0,16-0,55$ \\
\hline
\end{tabular}

Khoảng cách 2 mép xương trung bình là $0,78 \mathrm{~mm}$. Bề dày ngoại cốt mạc tại điếm xương mũi dày nhất với trung bình là $0,42 \mathrm{~mm}$.

Xét mối liên quan giữa bề dày ngoại cốt mạc tại điểm xương trán với các điểm còn lại chúng tồi có bảng sau:

Bảng 6: Mối liên quan giữa bề dày ngoai cốt mac tại điểm xương trán và điểm xương mũi

\begin{tabular}{|c|c|c|}
\hline $\begin{array}{c}\text { Bề dày ngoại cốt } \\
\text { mạc tại điểm } \\
\text { xương trán }\end{array}$ & $\begin{array}{c}\text { Hề số } \\
\text { tướng } \\
\text { quan (r) }\end{array}$ & $\begin{array}{c}\text { Giá trị } \\
\mathbf{p}\end{array}$ \\
\hline $\begin{array}{c}\text { Bề dày ngoại cốt mạc } \\
\text { tại điểm xương mứi }\end{array}$ & 0,81 & $\mathbf{0 , 0 4 8}$ \\
\hline \multicolumn{3}{|c|}{ Phương trình hối quy } \\
\hline Hệ số phương trình & 0,72 & $\mathbf{0 , 0 4 8}$ \\
\hline Hăng số & 0,07 & 0,551 \\
\hline
\end{tabular}

Nghiên cứu tìm thấy mối tương quan thuân và mạnh giữa bề dày ngoại cốt mạc tại điểm xương trán và điểm xương mũi. Từ đó, chúng tôi xây dựng được phương trình hồi quy như sau:

3.4. Bề dày ngoại cốt mạc tại điểm xương trán $=0,72 \times$ Bề dày ngoại cốt mạc tại điểm xương mũi $+0,07$

Bảng 7: Liên quan giữa bề dày ngoại côt mạc tại điểm xương trán và trung điểm khe khớp

\begin{tabular}{|c|c|c|}
\hline $\begin{array}{c}\text { Bề dày ngoại cốt mạc } \\
\text { tại điểm xương trán }\end{array}$ & $\begin{array}{c}\text { Hệ số } \\
\text { tương } \\
\text { quan (r) }\end{array}$ & $\begin{array}{c}\text { Giá } \\
\text { trị p }\end{array}$ \\
\hline $\begin{array}{c}\text { Bề dày ngoai cốt mạc } \\
\text { tại trung điểm khe khớp }\end{array}$ & 0,89 & 0,017 \\
\hline
\end{tabular}




\begin{tabular}{|c|c|c|}
\hline \multicolumn{3}{|c|}{ Phương trình hồi quy } \\
\hline Hệ số phương trình & 0,92 & 0,017 \\
\hline Hằng số & 0,02 & 0,855 \\
\hline
\end{tabular}

Nghiên cứu tìm thấy mối tương quan thuân và mạnh giữa bề dày ngoại cốt mạc tại điểm xương trán và trung điểm khe khớp. Từ đó, chúng tôi xây dựng được phương trình hồi quy như sau: Bề dày ngoại cốt mạc tại điểm xương trán $=0,92 \times$ Bề dày ngoại cốt mạc tại trung điểm khe khớp $+0,02$

\section{BÀN LUÂN}

4.1. Hình dạng xương mũi. Về hình dạng xương mũi nhìn thằng, nghiên cứu của chúng tôi cho thấy đa số xương mũi của người Việt có hình tứ giác, loại có bờ ngoài xương thẳng và hơi nghiêng ở hai bên (loại $A$ )chiếm $57,6 \%$, tiếp theo là loại bờ ngoài xương bị lõm (loại B) với 30,3\%.
Kết quả này phù hợp với mô tả của tác giả Trần Thị Anh Túvào năm 2003 trên 30 thi hài người Việt( ${ }^{(4)}$. Tuy nhiên tác giả Anh Tú chỉ dừng lại ở mổ tả hình dạng xương chứ không có xác định tỉ lệ của từng loai như nghiên cứu của chúng tôi.

So sánh với hình dạng xương của các chủng tộc trên thế giới, vào năm 1982, tác giả Lang và Baumeister đã phân loại hình dạng xương của người Đức thành 8 loại. Đến năm 2005, tác giả Hwang cho rằng cách phân loại này quá phức tạp và đã rút gọn 8 loại của tác giả Lang thành 5 loại khi phân tích hình dạng xương mũi người Hàn Quốc,và cách phân loại rút gọn này được áp dụng rộng rãi trong các nghiên cứu sau này ${ }^{(1)}$. Kết quả về hình dạng xương mũi của các nghiên cứuđược trình bày trong bảng sau:

\section{Bảng 8. So sánh các loai hình dang xương mưi trong các nghiên cứu}

\begin{tabular}{|c|c|c|c|c|c|c|}
\hline Nghiên cứu & Chưng tộc & A (\%) & B (\%) & C (\%) & D (\%) & E (\%) \\
\hline Lang $^{(1)}$ & Đức & 68,3 & 10,1 & 1,3 & 10,1 & 10,1 \\
\hline Hwang (1) & Hàn Quốc & 43,2 & 52,3 & 4,5 & 0 & 0 \\
\hline Prado (7) & Brazil & 49,5 & 27,8 & 13,4 & 2,1 & 7,2 \\
\hline Chúng tôi & Việt & 57,6 & 30,3 & 3 & 6,1 & 3 \\
\hline
\end{tabular}

Theo bảng trên, người Hàn Quốc chỉ có 3 loại hình dạng xương, trong khi các chủng tộc khác có đầy đủ cả 5 loại. ở người Đức, nhiêu nhất là loại $A$ và ít nhất là loai $C$; ở người Hàn Quốc thì nhiêu nhất lại là loại $B$; người Brazil và người Việt có tỉ lệ loại $A$ và loại $B$ khá tương đồng, nhưng ở người Brazil loại ít nhất là loại $D$ còn người Việt lại là loại $C$ và $E$. Như vậy, nhìn chung các chủng tộc đều có xương mũi chủ yếu là loại $A$ và $B$, tuy nhiên về tỉ lệ phân bố ở từng loại có sự khác biệt.

Về hình dạng xương mũi nhìn nghiêng, tại Việt Nam, theo sự hiểu biết của chúng tôi, tính tới thời điểm hiện tại chưa có tác giả nào đề cập đến nội dung này trong nghiên cứu của mình. Trên thế giới, vào năm 2015, tác giả Lazovic đã tiến hành khảo sát 44 thi hài từ trường Đại học $Y$ khoa Belgrade, Serbia và cho kết quả tỉ lể xương mũi chiếm đa số là hình $\mathrm{S}$ với $88 \%{ }^{(5)}$. Tuy nhiên, trong nghiên cứu của chúng tôi, đa số xương mũi người Việt lại có hình $\mathrm{V}$ với tỉ lệ là $78,8 \%$. Ngoài ra nghiên cứu còn tìm thấy sự khác biệt có ý nghĩa thống kê về hình dạng xương và điểm gù xương, trong đó xương mũi có điểm gù thì đa số sẽ có hình $S$ khi nhìn nghiêng $(p<0,001)$. Như vậy, điểm gù xương quyết định đến hình dạng của xương mũi. Bên cạnh đó, có thể thấy người Châu Âu đa số là có xương mũi hình $S$, trong khi người Việt lai có hình $\mathrm{V}$ là chủ yếu. Điều này có thể xuất phát từ những khác biệt về mặt chủng tộc dẫn đến đặc điểm cấu trúc xương mũi hoàn toà̀n khác nhau.
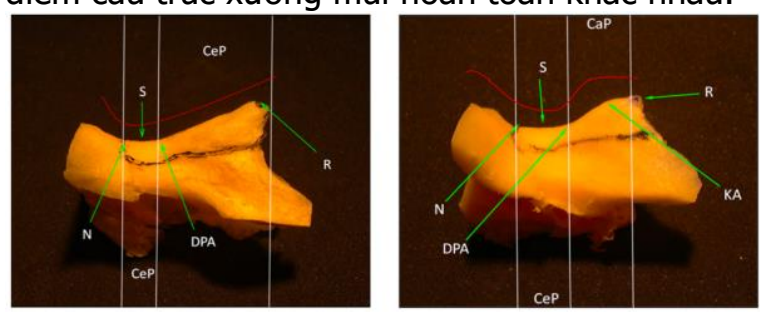

Hình 4. Hình dạng xương mũi nhin nghiêng theo tác giả Lazovic (5)

4.2. Hình dạng khớp mũi trán. Tương tự như hình dạng xương mũi nhìn nghiêng, về hình dạng của khớp mũi trán của người Việt, chúng tôi cũng chưa tìm thấy nghiên cứu nào mô tả về đặc điểm này. Theo kêt quả của chúng tôi, khớp mũi trán người Việt chiếm tỉ lệ cao nhất là hình $\mathrm{B}$ (chiếm 45,5\%) với khớp hình cong, sau đó là hình $\mathrm{A}$ (khớp hình đường thẳng) và hình $\mathrm{C}$ (khớp hình bán nguyệt) với tỉ lệ tương ứng là $21,2 \%$ và $15,1 \%$. Đây là cách phân loại theo tác giả Oetteking khi ông tiến hành phẩn loại khớp mũi trán trên 88 so người Mỹ (California). Và chính những mô tả và phân loại này đã trở thành cơ sở cho tác giả Hefner J.T đưa ra phân loại rút gọn hơn vào năm 2016, chỉ còn 4 loại khớp mũi trán ${ }^{(6)}$. Kết quả của các nghiên cứu được trình bày trong bảng sau:

Bảng 9. So sánh các loại hình dạng khớp mũi 
trán trong các nghiên cứu(6)

\begin{tabular}{|c|c|c|c|c|}
\hline Chủng tộc & $\begin{array}{c}\text { Loại } 1 \\
(\%)\end{array}$ & $\begin{array}{c}\text { Loại } 2 \\
(\%)\end{array}$ & $\begin{array}{c}\text { Loai } 3 \\
(\%)\end{array}$ & $\begin{array}{l}\text { Loai } 4 \\
(\%)\end{array}$ \\
\hline Người Mỹ(Da đen) & 50 & 30 & 10 & 10 \\
\hline $\begin{array}{l}\text { Người Mỹ (Da } \\
\text { trắng) }\end{array}$ & 100 & 0 & 0 & 0 \\
\hline $\begin{array}{l}\text { Quần đảo Thái } \\
\text { Bình Dương }\end{array}$ & 54 & 32 & 8 & 6 \\
\hline Thái Lan & 29 & 45 & 7 & 20 \\
\hline $\begin{array}{l}\text { Người Viêtt } \\
\text { (chúng tối) }\end{array}$ & 60,6 & 30,3 & 3 & 6,1 \\
\hline
\end{tabular}

Như vậy, phân bố về tỉ lệ các loại khớp mũi trán của người Việt khá tương đồng với các chủng tộc khác trong khu vực, chỉ có Thái Lan là có khác biệt là tỉ lệ loại 2 chiếm cao nhất. Đặc biệt nhất là $100 \%$ người Mỹ da trắng có khớp mũi trán loại 1 . Đây có thể là đặc trưng điển hình để phân loại theo chủng tộc.

Khớp mũi tránlà phần đỉnh và là phần vững chắc nhất của xương mũi. Nó đóng vai trò như một bệ đõ xương, hỗ trợ và củng cố vùng giữa mũi. So với các vùng khác, khớp mũi trán đóng góp ít hơn vào sự phát triển của khuôn mặt. Tuy nhiên, nó có thể có tầm quan trọng về mặt di truyền học đối với hình dạng của vùng giữa mặt, mặc dù mối liên quan của cấu trúc này với các vùng giữa mặt khác và với các số đo sọ não khác chưa được khám phá(6).

4.3. Mô học khớp mũi trán. Qua quan sát hình ảnh mô học, chúng tôi thấy xương trán và xương mũi đều được bao bọc bởi màng ngoài xương, trên hình ảnh vi thể có thể thấy màng ngoài xương gồm nhiều bó sợi collagen chạy song song với bề mặt xương, xen giữa các bó sợi collagen là mô liên kết lỏng lẻo không bắt màu thuốc nhuôm. Ở các vị trí khác nhau thì bề dày màng ngoài xương cũng khác nhau.Kết quả này trùng khớp với nghiên cứu của tác giả Tsai F.C đã tiến hành vào năm 2010 trên 20 mẫu mô nhuộm HE.Tác giả cũngkhẳng định rằng màng xương và xương được liên kết với nhau bởi các sợi Sharpeyxuyên vào khớp mũi trán. Khoảng cách từ khớp mũi trán đến điểm Nasion là $1,3 \pm$ $0,6 \mathrm{~mm}$. Màng xương ở phía trên dày hơn màng xương ở phía dưới khớp. Nam giới có màng xương tương đối dày hơn $(1,41 \pm 0,49 \mathrm{~mm})$ so với nữ $(1,18 \pm 0,5 \mathrm{~mm})$, và sự khác biệt này có ý nghĩa thống kê $(p<0,001)^{(8)}$.

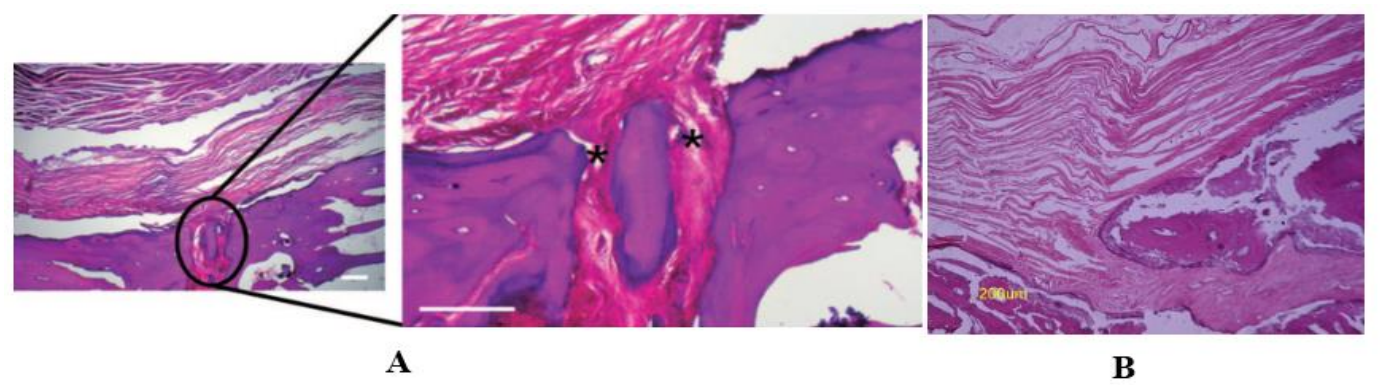

Hinh 5. Hinh ảnh mô học về sợi Sharpey tại khớp mũi trán của tác giả Tsai F.C (A) và nghiên cứu của chúng tôi (B)

Trong phẫu thuật nâng mũi, mảnh cây ghép được cấy vào dưới da hoặc ở dưới màng xương. Hiện nay cấy ghép dưới màng xương được chấp nhận rộng rãi hơn ở châu Á vì nó ổn định và nhìn tự nhiên hơn khi cấy ghép dưới da ${ }^{(8)}$. Tuy nhiên khi thực hiện cấy ghép dưới màng xương thì độ dày màng ngoài xương cực kỳ quan trọng. Qua mẫu nghiên cứu mô học và những nghiên cứu khác ở nước ngoài đều cho thây độ dày màng ngoài xương ở vị trí trên khớp trán mũi lớn hơn dưới khớp trán mũi, tuy vậy tại vị trí khớp trán mũi các bó sợi collagen chui vào khe khớp (còn gọi là sợi Sharpey), do khớp trán mũi là dạng khớp khâu hình răng cưa nên các bó sợi này bám rất chắc chắn, chính điều này làm cản trở quá trình cấy ghép vật liệu nhân tạo xuống dưới màng xương. Như vậy, silicone được cấy dưới màng ngoài xương ở vùng gốc mũi sẽ dể dàng hơn ở đường khớp gian mũi và việc nâng mũi sử dụng silicone cấy ghép dưới màng xương tại vùng gốc mũi cũng làm mũi trông tự nhiên, ổn định và có thể ngăn chặn được sự di lệch.

\section{KẾT LUẬN}

Kết quả của nghiên cứu phần nào đã cung cấp thêm những thông tin cần thiết ứng dụng cho lĩnh vực thẩm mỹ mũi đồng thời làm phong phú thêm nguồn tài liệu tham khảo cho khoa học nhận dạng và pháp y.

Ngoài ra, cần có các nghiên cứu chi tiết hơn về giải phẫu mô học của xương mũi với số liệu lớn, phối hợp với cáckỹ thuật cấy ghép vật liệu nhân tạo trong phẫu thuật nâng mũi nhằm nâng cao chất lượng, giảm biểnh chứng và tăng tỷ lệ thành công.

\section{TÀI LIỆU THAM KHẢO}


1. Hwang T.S, Song J, Yoona $H$, et al (2005) "Morphometry of the nasal bones and piriform apertures in Koreans". Annals of Anatomy, 187, pp. 411-414.

2. Lee S.E., Yang T.Y, Han G.S, et al (2008) "Analysis of the nasal bone and nasal pyramid by three- dimensional computed tomography". Eur. Arch. Otorhinolaryngol, 265, pp. 421-424.

3. Williams B.A, Rogers T (2006) "Evaluating the accuracy and precision of cranial morphological traits for sex determination". J. Forensic Sci, 51, pp. 729-735.

4. Trân Thị Anh Tú (2003) Hình thái, cấu trúc tháp mũi người trưởng thành, Luận án tiến sỹ y học, Đai họ Y Dược TP Hồ Chí Minh, tr. 30-60.

5. Lazovic G.D, Daniel R.K, Janosevic L.B, et al (2015) "Rhinoplasty: The Nasal Bones - Anatomy and Analysis". Aesthetic Surgery Journal, 35 (3), pp. $255-263$

6. Hefner J.T, Linde K.C (2018) Atlas of Human Cranial Macromorphoscopic Traits, Elsevier Inc, pp. 155-171.

7. Prado F.B, Caldas R.A, Rossi A.C, et al (2011) "Piriform Aperture Morphometry and Nasal Bones Morphology in Brazilian Population by PosteroAnterior Caldwell Radiographys". Int. J. Morphol, 29 (2), pp. 393-398.

8. Tsai F.C, Liao C.K, et al (2010) "Analysis of Nasal Periosteum and Nasofrontal Suture with Clinical Implications for Dorsal Nasal Augmentation". Plastic And Reconstructive Surgery, 126 (3), pp. 1037-1047.

\section{THỰC TRANG SÂU RĂNG CỦA MộT NHÓM NGƯờI KHIẾM THI TẠI MộT SỐ QUÂ̂N Ở HÀ NộI NĂM 2020 - 2021}

\section{TÓM TẮT}

Mục tiêu: Nghiên cứu nhằm đánh giá thực trạng sâu rắng của người khiếm thị tai một số quẩn ở Hà Nội. Phương pháp nghiên cứu: Nghiên cứu mô tả cắt ngang. Kết quả: Trong tổng số 151 người khiếm thị (76 nam, 75 nữ) đến khám có 63 người bị sâu răng, tỷ lệ sâu răng là $41.7 \%$. Chỉ số sâu mất trám trung bình là 3.06. Số răng mất trung bình là 1.96. Số răng được trám trung bình là 0.22 . Kết luận: Cần có những biện pháp hố trơ giáo dục, can thiệp điều trị kịp thời, giúp cho người khiếm thị được quan tâm, chăm sóc tốt hơn.

Tư khóa: Người khiếm thị, sâu răng.

\section{SUMMARY}

PREVALENCE OF DENTAL CARIES OF

VISUALLY IMPAIRED INDIVIDUALS IN SOME DISTRICTS OF HA NOI

Objective: To assess the prevalence of dental caries in visually impaired individuals in some districts of $\mathrm{Ha}$ Noi. Subjects and methods: This crosssectional study was carried out on 151 visually impaired individuals in some district of $\mathrm{Ha}$ Noi. Results and conclusions: In the study, $41.7 \%$ of individuals had dental caries. The overall mean number of DMFT was 3.06; mean number of missing teeth was 1.96; and mean number of filled teeth was 0.22 . caries.

Keywords: Visually impaired individuals, dental

*Trường Đại học Y Hà Nội

Chiu trách nhiếm chính: Võ Trương Như Ngọc

Email: votruongnhungoc@gmail.com

Ngày nhận bài: 5/4/2021

Ngày phản biện khoa học: 6/5/2021

Ngày duyệt bài: 22/5/2021

\section{I. ĐẶT VẤN ĐỀ}

Trong nhóm bệnh răng miệng thì sâu răng là bệnh rất phổ biến, gặp ở tất cả các lứa tuổi, mọi quốc gia trên thế giới. Bệnh sâu răng nếu không được điêuu trị kịp thời sẽ dẫn đến những biến chứng nguy hiểm như viêm tủy răng, viêm quanh cuống, ảnh hưởng nặng nề tới sức nhai, phát âm, thẩm mỹ.

Người khiếm thị thường khó tiếp cận với các biện pháp thông tin giáo dục truyền thông cũng như gặp khó khăn trong việc chăm sóc răng miệng. Hơn nữa, bản thân người khiếm thị thường có cuộc sống, hoàn cảnh khó khăn. Chỉ khi có triệu chứng đau răng rôi mới có nhu câu điêu trị. Mặt khác ở nước ta hiện nay những điều tra về bệnh sâu răng trên người khiếm thị chưa có nhiêu. Vì vậy, chúng tôi tiến hành nghiên cứu này với mục tiêu nhận xét thực trạng sâu răng của người khiếm thị tại một số quận ở Hà Nội năm 2020 - 2021.

\section{II. ĐỐl TƯƠNG VÀ PHƯƠNG PHÁP NGHIÊN CỨU}

2.1. Thời gian và địa điểm nghiên cứu: Ngày 14 tháng 3 năm 2021 tại nhà A5 bệnh viện Đại học Y Hà Nội.

2.2. Đối tượng nghiên cứu, Là người khiếm thị từ hội người mù một số quận ở Hà Nội

Thiết kế nghiên cứu, cõ̃ mẫu, cách chọn mẫu

Thiết kế nghiên cứu: là nghiên cứu cắt ngang mô tả

Cỗ mẫu được tính theo công thức:

$n=\frac{Z^{2}(1-a / 2) p(1-p)}{d^{2}}$ 